\title{
Low doses of ionizing radiation suppress doxorubicin-induced senescence-like phenotypes by activation of ERK1/2 and suppression of p38 kinase in MCF7 human breast cancer cells
}

\author{
JAE-SIK SHIN ${ }^{1,2 *}$, SANG HYEOK WOO ${ }^{3 *}$, HYUNG-CHAHN LEE ${ }^{3 *}$, SEUNG-WOO HONG $^{1}$, \\ DOO-HYUN YOO ${ }^{3}$, SEOK-IL HONG ${ }^{3}$, WANG-JAE LEE ${ }^{1}$, MYEONG-SOK LEE ${ }^{4}$, YOUNG-WOO JIN ${ }^{5}$, \\ SUNGKWAN AN ${ }^{2}$, DONG-HOON JIN ${ }^{1,4}$ and IN-CHUL PARK ${ }^{3}$
}

\begin{abstract}
${ }^{1}$ Department of Anatomy and Tumor Immnunity Medical Research Center, Seoul National University College of Medicine, Seoul 110-799; ${ }^{2}$ Department of Microbial Engineering, Konkuk University, Seoul 143-701; ${ }^{3}$ Division of Radiation Cancer Research, Korea Institute of Radiological and Medical Sciences, Seoul 139-706; ${ }^{4}$ Research Center for Women's Diseases, Division of Biological Sciences, Sookmyung Women's University, Seoul 140-742;

${ }^{5}$ Radiation Health Research Institute, Korea Hydro and Nuclear Power Co. Ltd., Seoul 132-703, Korea
\end{abstract}

Received December 3, 2009; Accepted February 8, 2010

DOI: 10.3892/ijo_00000630

\begin{abstract}
Low-dose radiation has a variety of effects on cellular activities, including the cell division cycle, apoptosis, proliferation and senescence. However, the effects of low doses of radiation remain controversial. In this study, we examined the effects of low-dose radiation on cellular senescence. We treated MCF7 cells with $0.01 \mu \mathrm{g} / \mathrm{ml}$ doxorubicin to induce replicative senescence, $2 \mathrm{~h}$ after exposure to low doses of ionizing radiation of $0.05,0.1$, or 0.2 Gy. The status of p53, senescence-associated B-galactosidase activity, p38 kinase levels, H2AX levels and ERK/MAPK levels were examined. Low doses of ionizing radiation inhibit doxorubicininduced senescence in human breast cancer MCF7 cells. The phosphorylations of both p38 MAP kinase and p53 induced by doxorubicin were suppressed by low doses of ionizing radiation. The senescence was inhibited without genomic damage, because the level of $\gamma-\mathrm{H} 2 \mathrm{AX}$ protein was not changed. Moreover, low doses of ionizing radiation inhibited senescence through the activation of ERK1/2. The results
\end{abstract}

Correspondence to: Dr Dong-Hoon Jin, Department of Anatomy and Tumor Immnunity Medical Research Center, Seoul National University College of Medicine, 28 Yeongeon-Dong, Seoul 110-799, Korea

E-mail: inno183@snu.ac.kr

Dr In-Chul Park, Division of Radiation Cancer Research, Korea Institute of Radiological and Medical Sciences, 215-4 GongneungDong, Seoul 139-706, Korea

E-mail: parkic@kcch.re.kr

${ }^{*}$ Contributed equally

Key words: doxorubicin, low dose of radiation, senescence, Erk1/2, p38 thus suggest that low doses of radiation suppress doxorubicin-induced replicative senescence through the inhibition of p38-dependent phosphorylation of p53 and by activation of ERK1/2, without genomic damage. Overall, our results suggest that low doses of ionizing radiation may have a protective role against replicative senescence induced by doxorubicin.

\section{Introduction}

In the last 10 years, many methods for inducing rapid onset of senescence have been developed. For example, human tumor cells may enter senescence by expressing tumor suppressor genes such as p53 (1), p21 (2), p16 (3), and Rb $(4,5)$. In normal fibroblasts, the expression of ras can induce rapid onset of senescence (6). Recently, our group found that $\mathrm{Bcl}-\mathrm{x}_{\mathrm{L}}$ and family proteins inhibited replicative senescence induced by expression of the tumor suppressor gene, p53, a relevant gene in senescence studies (1).

Recent work has shown that exposure of various cancer cells to low doses of anti-cancer drugs such as doxorubicin, cisplatin, taxol, or etoposide, leads to replicative senescence (7-9); high drug doses do not have this effect. Doxorubicin, an anthracycline antibiotic, is one of the most important anticancer agents for solid tumors (10). The tumor suppressor gene product $\mathrm{p} 53$ accumulates in response to genotoxic damage that occurs after exposure to doxorubicin (11). Accumulated p53 can trigger replicative senescence in tumor cells. Thus, doxorubicin can induce not only apoptosis via the activation of caspases and disruption of mitochondrial membrane potential $(12,13)$, but also senescence.

Recently, there has been increasing interest in the biological effects of low doses of ionizing radiation arising from natural and environmental exposure. Low-dose irradiation has diverse effects on genomic DNA, such as protection from mutation (14) or induction of mutation (15), and also causes changes in the cell division cycle (16). These events result 
from alterations in differential signal transduction pathways. Recently, one research group reported that low doses of ionizing radiation enhanced longevity in mice and pigs (17), whereas another group reported that replicative senescence was induced by X-ray irradiation of normal human dermal fibroblasts (18) and human lung carcinoma cells of the H1299 line (19), implying a relationship between low-dose irradiation, aging and cellular senescence. More work in this area is needed.

A recent study showed that extracellular-signal-regulated kinase (ERK) activity in photo-aged skin was reduced compared with the activities of other kinases such as JNK/SAPK and p38 MAPK (20). It has also been reported that ERK enhanced the proliferation of normal human diploid cells (21). Thus, there is a relationship between ERK activity on the one hand, and aging and proliferation on the other. The detailed mechanisms of ERK involvement in these cellular events are not clear. Here we demonstrate that low doses of ionizing radiation inhibit replicative senescence induced by doxorubicin in tumor cells. The inhibitory effect was due to the ERK activation, which inhibited doxorubicin-induced p53-p38 pathway. Our results will be helpful to understand the biological effects of low-dose ionizing radiation.

\section{Materials and methods}

Cell culture. MCF7 human breast cancer cells were cultured under $5 \%(\mathrm{v} / \mathrm{v}) \mathrm{CO}_{2}$ at $37^{\circ} \mathrm{C}$ in RPMI medium (Gibco BRL; Grand Island, NY) with glucose and $10 \%(\mathrm{v} / \mathrm{v})$ fetal bovine serum (hyclone), penicillin $(100 \mathrm{U} / \mathrm{ml})$ and streptomycin $(100 \mu \mathrm{g} / \mathrm{ml})$. Radiation source was $137 \mathrm{Cs} \gamma$-ray (KIRAMS, Korea) at a dose rate of $0.3 \mathrm{~Gy} / \mathrm{min}$.

Senescence-associated $\beta$-galactosidase (SA- $\beta$-Gal) analysis. Cells were washed in PBS and fixed in a solution of $0.25 \%$ (w/v) glutaraldehyde in PBS with $2 \mathrm{mM} \mathrm{MgCl}_{2}$, for $20 \mathrm{~min}$ at room temperature. SA- $\beta-$ Gal activity at $\mathrm{pH} 6.0$ was assayed as previously described $(8,22)$.

Cell cytotoxicity. Cell viability was determined by trypan blue exclusion, counting at least 300 cells of each culture. We used $0.05,0.1$, or 0.2 Gy of ionizing radiation before treatment with doxorubicin at $0.01 \mu \mathrm{g} / \mathrm{ml}$. After 4,5 , or 6 days of further incubation, the numbers of trypan blue-stained cells were counted.

Western blots. Cells lysates were prepared in RIPA buffer [50 mM Tris-HCl, $50 \mathrm{mM} \mathrm{NaCl}, 1 \mu \mathrm{M}$ EGTA, $1 \%$ (v/v) Triton X-100, $50 \mathrm{mM} \mathrm{NaF}, 5 \mathrm{mM} \mathrm{Na} \mathrm{VO}_{4}, 10 \mathrm{mM} \mathrm{Na}_{4} \mathrm{P}_{2} \mathrm{O}_{7}$, $0.1 \mathrm{mM}$ phenylmethylsulfonyl fluoride, $1 \mu \mathrm{g} / \mathrm{ml}$ aprotinin, $1 \mu \mathrm{g} / \mathrm{ml}$ pepstatin A, $1 \mu \mathrm{g} / \mathrm{ml}$ leupeptin, and $1 \mathrm{mM}$ DTT; $\mathrm{pH}$ 7.5]. Extracts were normalized for protein concentration using the Bradford assay, and $20 \mu \mathrm{g}$ of total cell protein per sample was subjected to sodium dodecylsulfate-polyacrylamide gel electrophoresis (SDS-PAGE), then transferred to a PolyScreen membrane (NEN; Boston, MA). Membranes were incubated in a solution of $5 \%(\mathrm{w} / \mathrm{v})$ non-fat dry milk in TBST buffer [20 mM Tris- $\mathrm{HCl}, 150 \mathrm{mM} \mathrm{NaCl}, 0.1 \%$ (v/v) Tween-20; $\mathrm{pH}$ 7.4] and probed with one of the following antibodies: anti-fibronectin (Transduction Technology, San
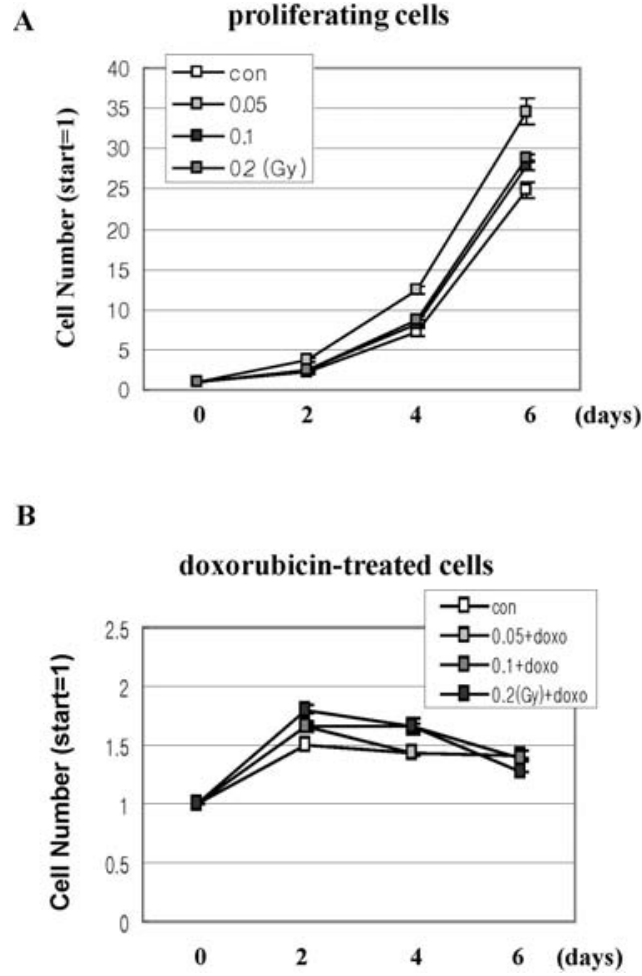

Figure 1. Effect of low doses of ionizing radiation on cell proliferation. (A) Normally growing MCF7 cells were treated with $0.05,0.1$, or 0.2 Gy of ionizing radiation and cell numbers were counted at the indicated times. (B) MCF7 cells were treated with $0.01 \mu \mathrm{g} / \mathrm{ml}$ of doxorubicin. The cells were then treated with $0.05,0.1$ or $0.2 \mathrm{~Gy}$ of ionizing radiation and cells were counted at the times indicated. The data represent the means and standard deviations of three independent experiments.

Jose, CA), anti-p-p38, anti-p38 (both from Cell Signaling Technology, Beverly, MA), anti- $\gamma$-H2AX (Upstate Biotechnology, Lake Placid, NY), anti-p-p53 (Ser-15), anti-p53, antiCDK4, or anti- $\gamma$-tubulin (the last four from Santa Cruz Biotechnology, Santa Cruz, CA). The primary antibodies were reacted with goat anti-mouse, goat anti-rabbit, or donkey anti-goat horseradish peroxidase-conjugated secondary antibodies, followed by ECL detection.

\section{Results}

Low doses of ionizing radiation suppress doxorubicininduced replicative senescence. To study the effect of low doses of ionizing radiation on replicative senescence, we employed a senescence system involving the anticancer drug, doxorubicin and tumor cells. Low doses of doxorubicin, such as 0.01 or $0.02 \mu \mathrm{g} / \mathrm{ml}$, can induce replicative senescence in such cells by causing phosphorylation of p53 and induction of p130, a member of the Rb family (23), without the induction of cell death (8). However, high doses of doxorubicin induce apoptosis via the activation of caspases and mitochondrial dysfunction $(12,13)$.

We treated MCF7 cells with $0.01 \mu \mathrm{g} / \mathrm{ml}$ doxorubicin to induce replicative senescence, $2 \mathrm{~h}$ after exposure to low doses of ionizing radiation of $0.05,0.1$, or $0.2 \mathrm{~Gy}$. Because low doses of ionizing radiation have been suggested to affect cell growth (20), we first examined the effects of radiation on cell proliferation (Fig. 1A) and cell death. Low doses (0.05, 
A

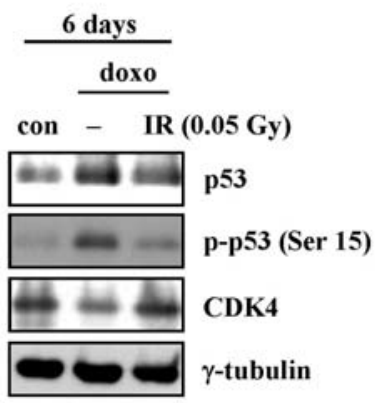

B

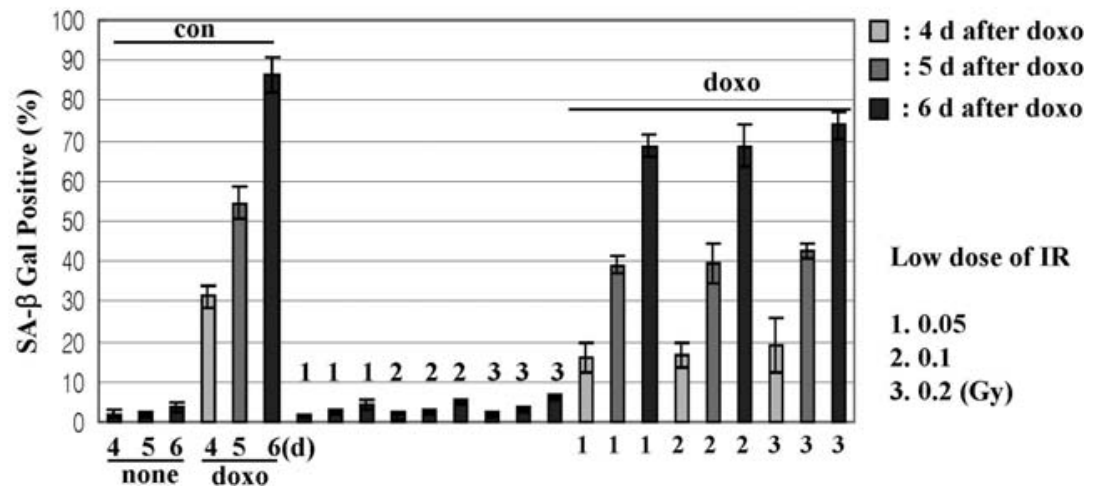

C

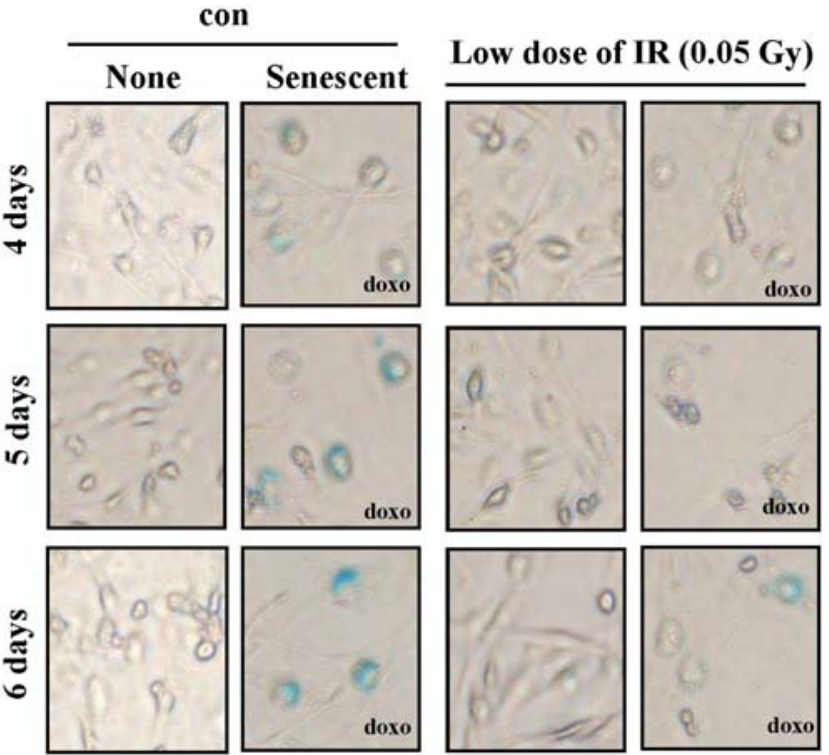

D

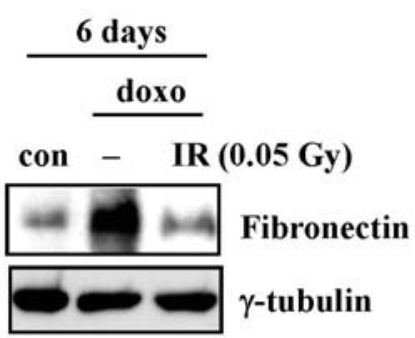

Figure 2. (A-D) Low doses of ionizing radiation inhibit doxorubicin-induced senescence. (A) Cells were exposed to 0.05 Gy of ionizing radiation $2 \mathrm{~h}$ after treatment with $0.01 \mu \mathrm{g} / \mathrm{ml}$ doxorubicin (doxo). Expression of p53, phospho-p53 and CDK4, at the indicated times after radiation treatment, was determined by immunoblotting analysis using $\gamma$-tubulin as control. (B) SA-ß-gal staining and (C) morphology were observed at the indicated times after treatment with 0.05 Gy of ionizing radiation in doxorubicin-treated MCF7 cells. The data are representative of three independent experiments. (D) Immunoblotting of a biochemical marker of senescence, fibronectin, at the indicated time points. 

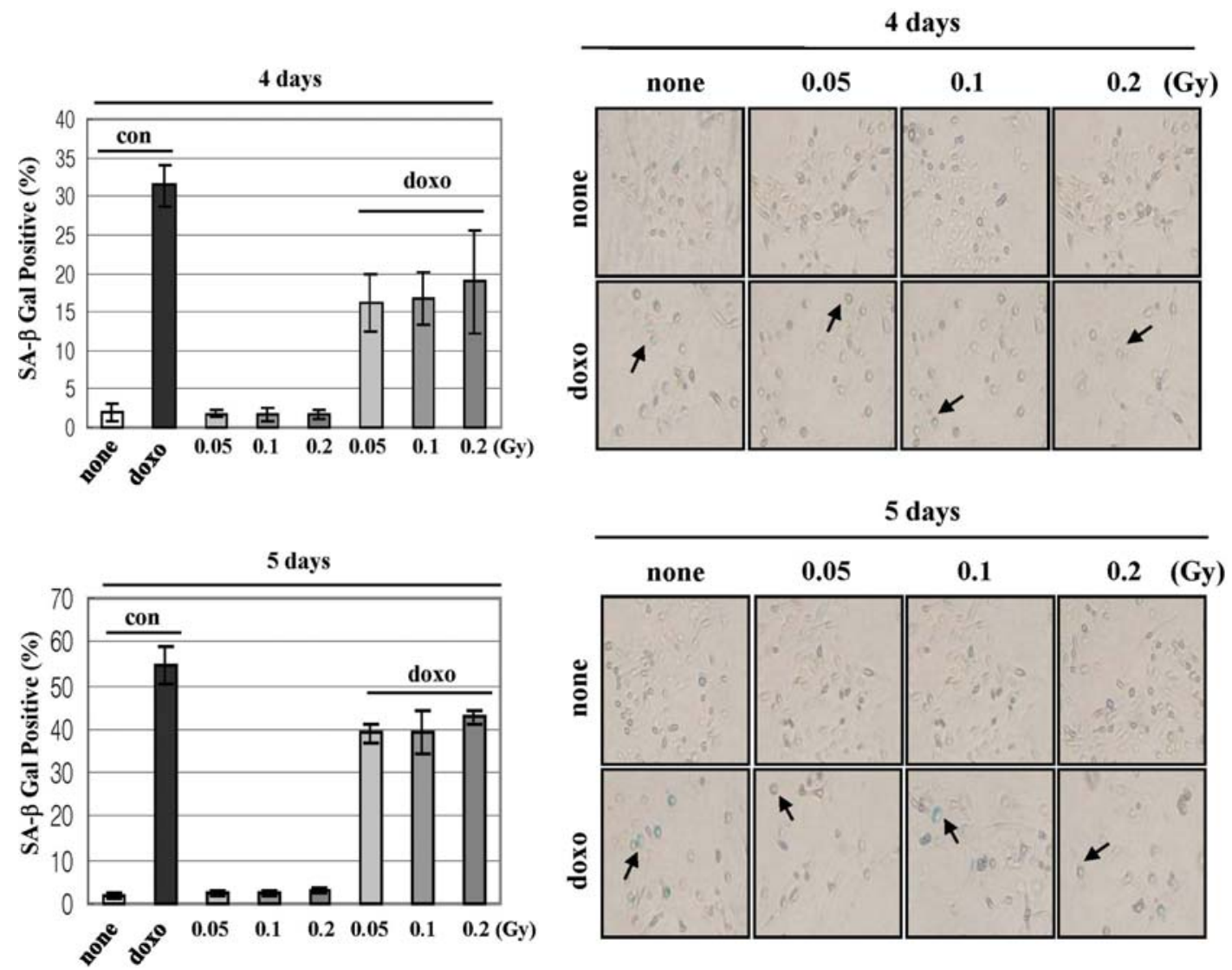

Figure 2. (E) The effects of low doses of ionizing radiation on senescence phenotypes at 4 or 5 days. SA- $\beta$-gal staining and morphology were observed at 4 or 5 days after treatment with 0.05 Gy of ionizing radiation in doxorubicin-treated MCF7 cells. The data are representative of three independent experiments.

0.1 , or $0.2 \mathrm{~Gy}$ ) of ionizing radiation slightly increased the total numbers of normally proliferating cells or doxorubicintreated cells (Fig. 1). Consistently, dead cells were absent among control and doxorubicin-treated MCF7 cells exposed to low doses of radiation (data not shown).

Recent studies showed that p53 activation is necessary for doxorubicin-induced senescence in MCF7 cells $(7,8)$. To evaluate the effects of low-radiation doses on doxorubicininduced replicative senescence in MCF7 cells, we first examined the status of p53. Low doses of radiation suppressed the phosphorylation of p53 by doxorubicin (Fig. 2A). In addition, CDK4 expression that was suppressed by doxorubicin recovered after low-dose ionizing radiation (Fig. 2A). We next examined senescence-associated Bgalactosidase (SA- - -Gal) activity, a specific cytoplasmic marker for senescent cells $(8,22)$, and also cell morphological characteristics. Cells were exposed to $0.05,0.1$, or $0.2 \mathrm{~Gy}$ for $2 \mathrm{~h}$ followed by doxorubicin $(0.01 \mu \mathrm{g} / \mathrm{ml})$ treatment and then assayed for SA-ß-Gal activity at 6 days (Fig. 2B). In comparison to cells treated with doxorubicin only, SA-B-Gal-positive cells decreased when cells were treated with both ionizing radiation and doxorubicin (Fig. 2B). Consistent with the appearance of SA- $\beta-G a l$ activity, the morphological characteristics of senescent cells (such cells are typically large and flattened) decreased in cells treated with doxorubicin after low-dose ionizing radiation
(Fig. 2C). In addition, fibronectin levels, which increase in senescent cells (24), were lower in cells treated with doxorubicin after ionizing radiation than in cells treated with doxorubicin only (Fig. 2D). These results suggest that low doses of ionizing radiation suppress replicative senescence induced by doxorubicin in MCF7 cells.

Low doses of ionizing radiation suppress activation of p38 kinase by doxorubicin. Recent studies have shown that p38 kinase expression accelerates senescence after DNA damage (28) and that the kinase is activated during senescence of human diploid fibroblasts (29). We have also found that the activity of p38 kinase is induced during p53-induced senescence in the human bladder cancer cell line EJ (1). This report showed that the phosphorylation of p38 kinase is insignificantly increased at 2 days and maximum at 4 days, indicating that p38 kinase is an important factor for senescence induction (1). In this study, senescence phenotypes were gradually induced at 4, 5 days after doxorubicin treatment (Fig. 2E) and maximum at 6 days (Fig. 2). However, senescence phenotypes by doxorubicin were almost induced until 3 days (data not shown), implying that 4 days after treatment with $0.01 \mu \mathrm{g} / \mathrm{ml}$ doxorubicin may be an initiation point of senescence. Based on these studies, we firstly examined the phosphorylation of p38 kinase at 4 days after doxorubicin treatment and the effect of low doses of ionizing radiation on its activity. The 
A

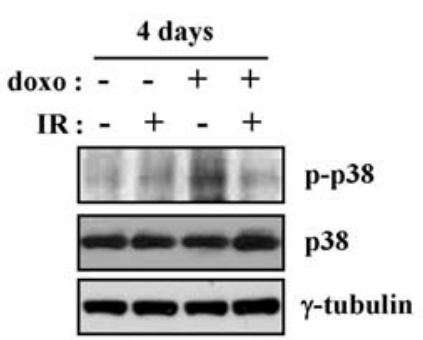

B

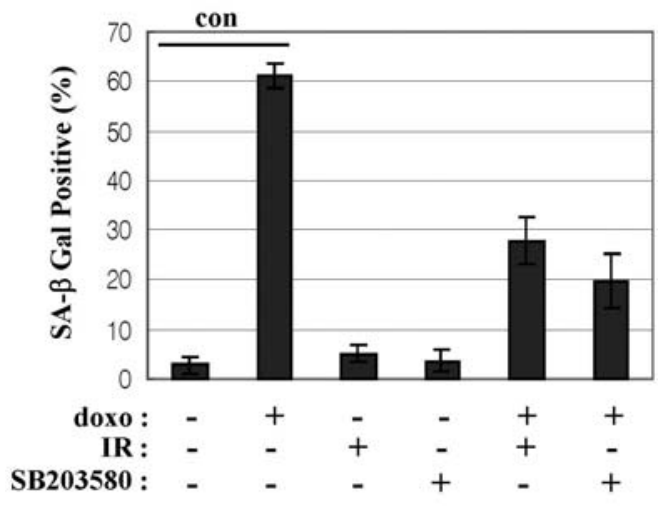

C

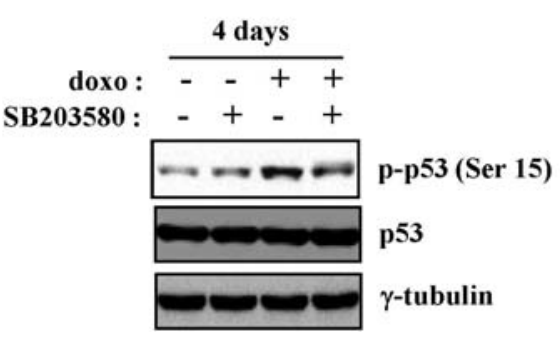

Figure 3. Low doses of ionizing radiation inhibit phosphorylation of p38 MAPK by doxorubicin. (A) Immunoblotting of phosphorylated p38 MAPK 4 days after exposure to 0.05 Gy ionizing radiation of doxorubicin-treated MCF7 cells. (B) Effect of p38 MAPK inhibitor on doxorubicin-induced senescence in MCF7 cells. MCF7 cells were treated with SB203580 $(10 \mu \mathrm{M})$ for $2 \mathrm{~h}$, and then treated with doxorubicin. SA-B-Gal-positive cells were counted 5 days after doxorubicin treatment. The data represent the means and standard deviations of three independent experiments. (C) Effect of p38 MAPK inhibitor on phosphorylation of p53 after doxorubicin treatment Phosphorylation was assessed 4 days after doxorubicin treatment that followed SB203580 exposure; $\gamma$-tubulin was used as control.

phosphorylation of p38 kinase significantly increased at 4 days after doxorubicin treatment was suppressed by low doses of ionizing radiation without changing protein levels of p38 kinase (Fig. 3A). Consistently, SA-ß-Gal activity was decreased in cells treated with doxorubicin following a chemical inhibitor of p38 kinase, SB203580 (Fig. 3B). These results suggest that $\mathrm{p} 38$ kinase is specifically required for senescence induction by doxorubicin and low doses of ionizing radiation can inhibit doxorubicin-induced senescence through suppression of p38 kinase in MCF7 cells.

Low doses of ionizing radiation thus suppressed the doxorubicin-induced phosphorylation of both p53 and p38
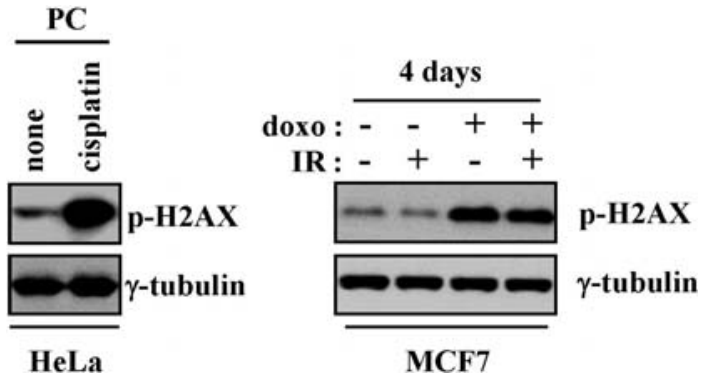

Figure 4. Low doses of ionizing radiation do not induce DNA damage Immunoblotting of a biochemical marker of DNA damage, $\mathrm{p}-\mathrm{H} 2 \mathrm{AX}, 4$ days after exposure to 0.05 Gy ionizing radiation of doxorubicin-treated MCF7 cells. HeLa cells were used as a positive control (PC). Cisplatin is a genotoxic agent, which induces the phosphorylation of H2AX.

kinase. Two studies have demonstrated that the phosphorylation of p53 is induced by p38 kinase after DNA damage $(30,31)$. We next examined whether low-dose ionizing radiation inhibits the phosphorylation of p53 via inactivation of p38 kinase. The phosphorylation of p53 in MCF7 cells treated with a combination of doxorubicin and a chemical inhibitor of p38 kinase, SB203580, was significantly decreased from control levels (Fig. 3C), implying that p38 kinase-dependent phosphorylation of p53 is essential for doxorubicin-induced senescence. These results suggest that low doses of ionizing radiation inhibit doxorubicin-induced senescence through suppression of p38 kinase-dependent phosphorylation of $\mathrm{p} 53$.

Low doses of ionizing radiation do not induce DNA damage in senescence induced by doxorubicin. Some studies have found that low doses of ionizing radiation induce DNA damage in tumor or normal cells (25). We next focused on H2AX, which is phosphorylated in DNA-damaged cells $(26,27)$. The phosphorylation of $\mathrm{H} 2 \mathrm{AX}$ was specifically increased only after doxorubicin treatment, and not in cells treated with ionizing radiation (Fig. 4), implying that low doses of ionizing radiation did not induce cellular stress such as DNA damage in normally proliferating cells.

The activation of ERK/MAPK by low doses of ionizing radiation is essential for inhibition of doxorubicin-induced senescence. A recent study showed that low doses of ionizing radiation positively regulated cell proliferation through the activation of ERK/MAPK (20). To investigate the effects of ERK/MAPK on doxorubicin-induced senescence, we examined ERK/MAPK levels in cells treated with low doses of ionizing radiation. ERK/MAPK was weakly induced by lowdose radiation alone, but was significantly increased in cells treated with a combination of a low dose of radiation and doxorubicin (Fig. 5A). We thus examined the effects of ERK/MAPK on the p38-p53 pathway induced by doxorubicin. Cells were treated with a chemical inhibitor of ERK/MAPK, PD980590, after exposure to a combination of a low dose of ionizing radiation and doxorubicin. The phosphorylation of both p38 and p53 that was inhibited by low doses of ionizing radiation was restored (Fig. 5B), implying that ERK/MAPK, which is activated by low doses of ionizing radiation, negatively regulated the p38-p53 
A

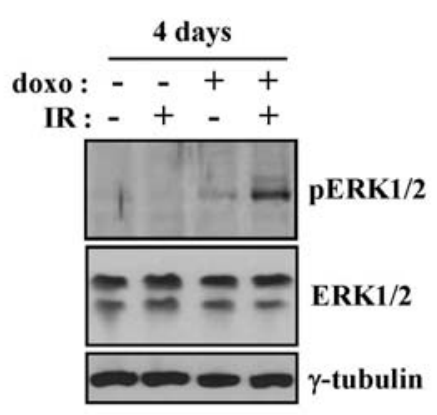

B

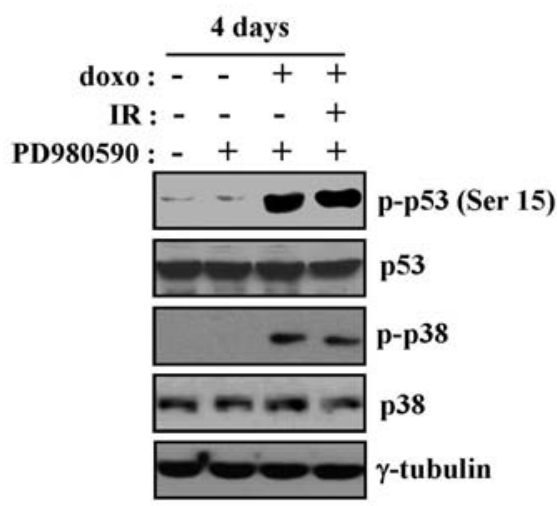

C

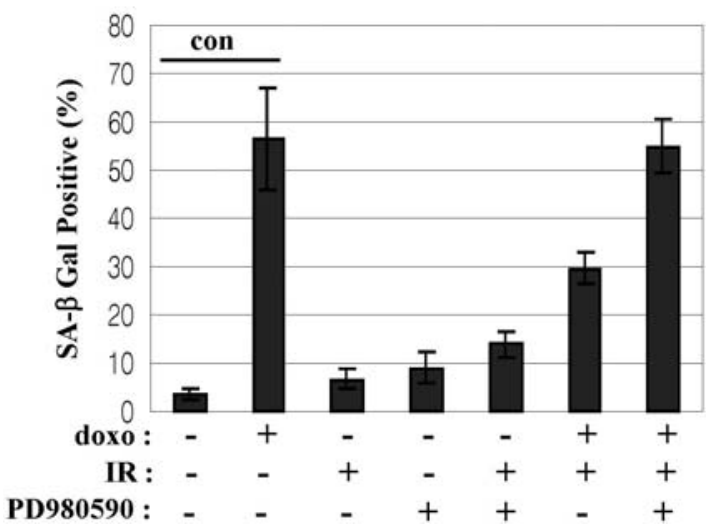

Figure 5. Low doses of ionizing radiation inhibit doxorubicin-induced senescence through activation of ERK/MAPK. (A) Cell lysates were prepared 4 days after exposure of MCF7 cells to 0.05 Gy of ionizing radiation, after prior treatment with doxorubicin, and were subjected to Western blot analysis. Total lysates were probed with anti-p-ERK1/2 and anti-ERK1/2. $\gamma$-tubulin was used as control. (B) Effect of the MEK inhibitor, PD980590, on doxorubicin-induced senescence. After doxorubicin treatment, cells were treated with $20 \mu \mathrm{M}$ PD980590 before exposure to ionizing radiation. Phosphorylation of ERK1/2, p38 MAPK, and p53 was analyzed after 4 days. $\gamma$-tubulin was used as a control. (C) Effect of MEK inhibitor on doxorubicininduced senescence in MCF7 cells. The number of SA-B-Gal-positive cells was counted after 5 days. Results represent the means and the standard deviations of three independent experiments.

pathway induced by doxorubicin. Consistently, SA-ß-Gal activity also significantly increased in cells treated with PD980590 (Fig. 5C). The SA-ß-Gal activity of cells treated with low doses of ionizing radiation was restored to control levels by treatment with PD98059. Thus, low doses of

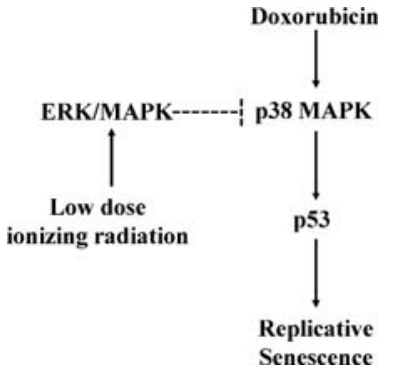

Figure 6. The diagram shows how low doses of ionizing radiation inhibit doxorubicin-induced senescence. Low doses of ionizing radiation induce the ERK/MAPK activation, which inhibits doxorubicin-induced p38-p53 pathway and eventually inhibits replicative senescence.

ionizing radiation inhibited doxorubicin-induced senescence through induction of ERK/MAPK activity.

\section{Discussion}

In this study, we first demonstrated the inhibitory effects of low doses of ionizing radiation on senescence. Treatment with low-dose radiation, which did not affect cell growth, inhibited senescence phenotypes in cells treated with doxorubicin. We found that the activation of ERK/MAPK by low-dose radiation is essential for the inhibition of senescence induced by doxorubicin.

Although some research groups have recently reported the effects of low doses of radiation on longevity and senescence $(17,32,33)$, the underlying molecular mechanisms remained unknown. We thus focused on the mechanisms by which low doses of ionizing radiation inhibit cellular senescence. Because treatment with low doses of doxorubicin, which does not affect cell growth, rapidly induces senescence in human tumor cells (23), we used the doxorubicin-induced senescence system to observe the effects of low doses of ionizing radiation on senescence. We report that low doses of radiation that do not affect cell proliferation inhibit senescence phenotypes induced by doxorubicin (Figs. 1 and 2).

To elucidate the molecular mechanisms by which lowdose radiation inhibits doxorubicin-induced senescence in MCF7 cells, we focused on the p38 kinase that is constitutively activated during irreversible growth arrest and senescence $(31,34)$. The present study shows that the phosphorylation of p38 kinase by doxorubicin is necessary for senescence induction (Fig. 3). Several lines of evidence indicate that p38 kinase is involved in the cellular commitment to senescence induction. First, the phosphorylation of p38 kinase was induced at 4 days after doxorubicin treatment. Second, senescence phenotypes were observed for 4 days after treatment with doxorubicin, while not observed otherwise until 3 days (data not shown). Thus, since the phosphorylation of p38 kinase required for senescence induction by doxorubicin was inhibited by low doses of ionizing radiation (Fig. 3A), it is likely that low doses of ionizing radiation inhibits senescence induction by preventing doxorubicin-induced phosphorylation of p38 kinase. This is further supported by the finding that a chemical inhibitor of p38 kinase, SB203580 was found to inhibit doxorubicin-induced senescence (Fig. 3B). Furthermore, the 
inhibition of p38 kinase by SB203580 resulted in the suppression of phospho-p53 (Fig. 3C). This notion is further supported by recent reports that p38 kinase immediately phosphorylates p53 $(30,35,36)$. These findings thus indicate that low doses of ionizing radiation inhibit doxorubicininduced senescence through suppression of the p38-p53 pathway.

Recent studies reported that DNA double-strand break (DSBs) in senescence process was highly observed (37). Interestingly, we showed that the phosphorylation of H2AX, as a marker of DNA damages, was induced after treatment with doxorubicin, but not by low doses of ionizing radiation (Fig. 4), implying that low doses of ionizing radiation may inhibit senescence without induction of DNA double-strand break (DSBs) in senescence processing by doxorubicin. However, the relationship between low doses of ionizing radiation and DNA double-strand break (DSBs) in replicative senescence remains to be elucidated.

Recent work has indicated that low-dose ionizing radiation induces the activation of ERK/MAPK and subsequently favors cell growth (20). Thus, the activation of ERK/MAPK by low doses of radiation affects the cell division cycle in normally proliferating cells (20). Here, we report that ERK/ MAPK is necessary for inhibition of doxorubicin-induced senescence (Fig. 5). Furthermore, ERK/MAPK inhibited induction of the p38-p53 pathway. Treatment with PD980590, a chemical inhibitor of ERK/MAPK, resulted in induction of the p38-p53 pathway in cells treated with a combination of a low dose of ionizing radiation and doxorubicin, implying that low doses of radiation inhibit doxorubicin-induced senescence through the activation of ERK/MAPK (Fig. 6). However, the relationship between the ERK/MAPK and p38p53 pathways remains unclear. Further research in this area is required.

In summary, we found that low doses of ionizing radiation inhibited doxorubicin-induced senescence. Our data indicate that activation of ERK/MAPK by radiation is essential for the inhibition of senescence phenotypes caused by doxorubicin, which induces the p38-p53 pathway in human breast cancer MCF7 cells. To examine whether low doses of ionizing radiation have an anti-senescence effect in other cellular system may help to understand the characteristics of low doses of ionizing radiation.

\section{Acknowledgements}

This work was supported by Grant No. R-2006-1-043 from the Ministry of Knowledge Economy, Korea.

\section{References}

1. Sugrue MM, Shin DY, Lee SW and Aaronson SA: Wild-type p53 triggers a rapid senescence program in human tumor cells lacking functional p53. Proc Natl Acad Sci USA 94: 9648-9653, 1997

2. Fang L, Igarashi M, Leung J, Sugrue MM, Lee SW and Aaronson SA: p2 1 Waf1/Cip1/Sdil induces permanent growth arrest with markers of replicative senescence in human tumor cells lacking functional p53. Oncogene 18: 2789-2797, 1999.

3. Uhrbom L, Nistér M and Westermark B: Induction of senescence in human malignant glioma cells by $\mathrm{p} 16^{\mathrm{INK} 4 \mathrm{~A}}$ Oncogene 15: 505-514, 1997.
4. Xu HJ, Zhou Y, Ji W, Perng GS, Kruzelock R, Kong CT, Bast RC, Mills GB, Li J and Hu SX: Re-expression of the retinoblastoma protein in tumor cells induces senescence and telomerase inhibition. Oncogene 15: 2589-2596, 1997.

5. Jung MS, Yun J, Chae HD, Kim JM, Kim SC, Choi TS and Shin DY: p53 and its homologues, p63 and p73, induce a replicative senescence through inactivation of NF-Y transcription factor. Oncogene 20: 5818-5825, 2001.

6. Serrano M, Lin AW, McCurrach ME, Beach D and Lowe SW: Oncogenic ras provokes premature cell senescence associated with accumulation of p53 and p16 ${ }^{\mathrm{INK} 4 \mathrm{a}}$. Cell 88: 593-602, 1997.

7. Chang BD, Xuan Y, Broude EV, Zhu H, Schott B, Fang J and Roninson IB: Role of p53 and p21 waf1/cip1 in senescence-like terminal proliferation arrest induced in human tumor cells by chemotherapeutic drugs. Oncogene 18: 4808-4818, 1999.

8. Elmore LW, Rehder CW, Di X, McChesney PA, Jackson-Cook CK, Gewirtz DA and Holt SE: Adriamycin-induced senescence in breast tumor cells involves functional p53 and telomere dysfunction. J Biol Chem 277: 35509-35515, 2002.

9. Han Z, Wei W, Dunaway S, Darnowski JW, Calabresi P, Sedivy J, Hendrickson EA, Balan KV, Pantazis P and Wyche JH: Role of p21 in apoptosis and senescence of human colon cancer cells treated with camptothecin. J Biol Chem 277: 17154-17160, 2002.

10. Bogush TA, Smirnova GB, Bogush EA and Robert J: A new method for the intravital assessment of the functional activity of the membrane transporters performing the efflux of antitumor preparations from the cells of solid tumor specimens. Antibiot Khimioter 44: 19-24, 1999.

11. Kurz EU, Douglas P and Lees-Miller SP: Doxorubicin activates ATM-dependent phosphorylation of multiple downstream targets in part through the generation of reactive oxygen species. J Biol Chem 279: 53272-53281, 2004.

12. Froesch BA, Aimé-Sempé C, Leber B, Andrews D and Reed JC: Inhibition of p53 transcriptional activity by $\mathrm{Bcl}-2$ requires its membrane-anchoring domain. J Biol Chem 274: 6469-6475, 1999.

13. Huigsloot M, Tijdens IB, Mulder GJ and van de Water B: Differential regulation of doxorubicin-induced mitochondrial dysfunction and apoptosis by Bcl-2 in mammary adenocarcinoma (MTLn3) cells. J Biol Chem 277: 35869-35879, 2002.

14. Amundson SA, Lee RA, Koch-Paiz CA, Bittner ML, Meltzer P, Trent JM and Fornace AJ Jr: Differential responses of stress genes to low dose-rate irradiation. Mol Cancer Res 1: 445-452, 2003.

15. Kumar PR, Mohankumar MN, Hamza VZ and Jeevanram RK: Dose-rate effect on the induction of HPRT mutants in human G0 lymphocytes exposed in vitro to gamma radiation. Radiat Res 165: 43-50, 2006.

16. Vávrová J, Rezácová M, Vokurková D and Psutka J: Cell cycle alteration, apoptosis and response of leukemic cell lines to gamma radiation with high- and low-dose rate. Physiol Res 53: $335-342,2004$

17. Caratero A, Courtade M, Bonnet L, Planel H and Caratero C: Effect of a continuous gamma irradiation at a very low dose on the life span of mice. Gerontology 44: 272-276, 1998.

18. Rave-Fränk M, Virsik-Köpp P, Pradier O, Nitsche M, Grünefeld S and Schmidberger $\mathrm{H}$ : In vitro response of human dermal fibroblasts to X-irradiation: relationship between radiation-induced clonogenic cell death, chromosome aberrations and markers of proliferative senescence or differentiation. Int J Radiat Biol 77: 1163-1174, 2001

19. Suzuki K, Mori I, Nakayama Y, Miyakoda M, Kodama S and Watanabe M: Radiation-induced senescence-like growth arrest requires TP53 function but not telomere shortening. Radiat Res 155: 248-253, 2001.

20. Shin MH, Rhie GE, Kim YK, Park CH, Cho KH, Kim KH, Eun $\mathrm{HC}$ and Chung $\mathrm{JH}: \mathrm{H}_{2} \mathrm{O}_{2}$ accumulation by catalase reduction changes MAP kinase signaling in aged human skin in vivo. J Invest Dermatol 125: 221-229, 2005.

21. Suzuki K, Kodama S and Watanabe M: Extremely low-dose ionizing radiation causes activation of mitogen-activated protein kinase pathway and enhances proliferation of normal human diploid cells. Cancer Res 61: 5396-5401, 2001.

22. Chang BD, Broude EV, Dokmanovic M, Zhu H, Ruth A, Xuan Y, Kandel ES, Lausch E, Christov $\mathrm{K}$ and Roninson IB: A senescence-like phenotype distinguishes tumor cells that undergo terminal proliferation arrest after exposure to anticancer agents. Cancer Res 59: 3761-3767, 1999. 
23. Jackson JG and Pereira-Smith OM: Primary and compensatory roles for RB family members at cell cycle gene promoters that are deacetylated and downregulated in doxorubicin-induced senescence of breast cancer cells. Mol Cell Biol 26: 2501-2510, 2006.

24. Kumazaki T, Robetorye RS, Robetorye SC and Smith JR: Fibronectin expression increases during in vitro cellular senescence: correlation with increased cell area. Exp Cell Res 195: $13-19,1991$

25. de Toledo SM, Asaad N, Venkatachalam P, Li L, Howell RW, Spitz DR and Azzam EI: Adaptive responses to low-dose/lowdose-rate gamma rays in normal human fibroblasts: the role of growth architecture and oxidative metabolism. Radiat Res 166: 849-857, 2006

26. Rogakou EP, Pilch DR, Orr AH, Ivanova VS and Bonner WM: DNA double-stranded breaks induce histone H2AX phosphorylation on serine 139. J Biol Chem 273: 5858-5868, 1998.

27. Rogakou EP, Boon C, Redon C and Bonner WM: Megabase chromatin domains involved in DNA double-strand breaks in vivo. J Cell Biol 146: 905-916, 1999.

28. Nelyudova A, Aksenov N, Pospelov V and Pospelova T: By blocking apoptosis, $\mathrm{Bcl}-2$ in p38-dependent manner promotes cell cycle arrest and accelerated senescence after DNA damage and serum withdrawal. Cell Cycle 6: 2171-2177, 2007.

29. Wang W, Chen JX, Liao R, Deng Q, Zhou JJ, Huang S and Sun P: Sequential activation of the MEK-extracellular signalregulated kinase and MKK3/6-p38 mitogen-activated protein kinase pathways mediates oncogenic ras-induced premature senescence. Mol Cell Biol 22: 3389-3403, 2002.

30. Bulavin DV, Saito S, Hollander MC, Sakaguchi K, Anderson CW, Appella E and Fornace AJ Jr: Phosphorylation of human p53 by p38 kinase coordinates $\mathrm{N}$-terminal phosphorylation and apoptosis in response to UV radiation. EMBO J 18: 6845-6854, 1999.
31. Wang $\mathrm{H}$, Wang $\mathrm{Z}$, Chen $\mathrm{J}$ and $\mathrm{Wu} \mathrm{J}$ : Apoptosis induced by $\mathrm{NO}$ via phosphorylation of p38 MAPK that stimulates NF-kappaB, p53 and caspase-3 activation in rabbit articular chondrocytes. Cell Biol Int 31: 1027-1035, 2007.

32. Tanaka S, Tanaka IB 3rd, Sasagawa S, Ichinohe K, Takabatake T, Matsushita S, Matsumoto T, Otsu H and Sato F: No lengthening of life span in mice continuously exposed to gamma rays at very low dose rates. Radiat Res 160: 376-379, 2003.

33. Moskalev AA and Zainullin VG: Longevity of Drosophila after exposure to low doses of radiation and etoposide. Adv Gerontol 10: 51-63, 2002.

34. Haq R, Brenton JD, Takahashi M, Finan D, Finkielsztein A, Damaraju S, Rottapel R and Zanke B: Constitutive p38HOG mitogen-activated protein kinase activation induces permanent cell cycle arrest and senescence. Cancer Res 62: 5076-5082, 2002.

35. Huang C, Ma WY, Maxiner A, Sun Y and Dong Z: p38 kinase mediates UV-induced phosphorylation of p53 protein at serine 389. J Biol Chem 274: 12229-12235, 1999.

36. Kim SJ, Hwang SG, Shin DY, Kang SS and Chun JS: p38 kinase regulates nitric oxide-induced apoptosis of articular chondrocytes by accumulating p53 via NFkappa B-dependent transcription and stabilization by serine 15 phosphorylation. J Biol Chem 277: 33501-33508, 2002.

37. Okada M, Okabe A, Uchihori Y, Kitamura H, Sekine E, Ebisawa S, Suzuki M and Okayasu R: Single extreme low dose/low-dose rate irradiation causes alteration in lifespan and genome instability in primary human cells. Br J Cancer 96: 1707-1710, 2007. 